\section{The effect of controlled mild hypothermia on large scald burns in a resuscitated rat model}

\author{
Nhi Tan, Henry C Thode Jr, Adam J. Singer \\ Department of Emergency Medicine, Stony Brook University, Stony Brook, NY, USA
}

Objective Early surface cooling of burns reduces pain, depth of injury and improves healing. We hypothesized that controlled mild hypothermia would also prolong survival in a fluid resuscitated rat model of large scald burns.

Methods Forty rats were anesthetized and a single full-thickness scald burn covering $40 \%$ of total body surface area was created on each of the rats. The rats were then randomized to hypothermia $(n=20)$ or no hypothermia $(n=20)$. Mild hypothermia (a reduction of $\left.2^{\circ} \mathrm{C}\right)$ was induced with intraperitoneal $4^{\circ} \mathrm{C}$ normal saline and ice packs. After 2 hours of hypothermia, the rats were rewarmed back to their baseline temperature with a heating pad. The control rats received room temperature intraperitoneal saline. The difference in survival between the groups was determined using Kaplan-Meier analysis and the log-rank test.

Results Hypothermia was induced in all experimental rats within a mean of 22 minutes (95\% confidence interval, 17 to 27). The number of normothermic and hypothermic rats that expired at each time interval were: at 1 hour, 4 vs. 0 ; at 10 hours, 2 from each group; at 24 hours, 0 vs. 1; at 48 hours, 2 vs. 2 ; at 72 hours, 1 vs. 1 ; and at 120 hours, 1 vs. 1 respectively. There were no differences in time to survival between the groups.

Conclusion Induction of brief, mild hypothermia does not prolong survival in a resuscitated rat model of large scald burns.

Keywords Burns; Resuscitation; Rats

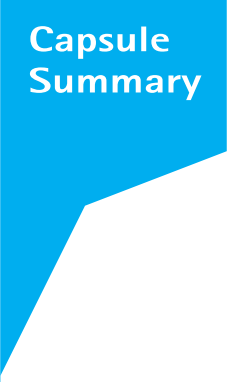

What is already known

Local cooling of burns improves outcomes, but there are concerns that induction of hypothermia, especially in large burns, will worsen outcomes. We have previously shown that induction of mild therapeutic hypothermia prolongs survival in a rat model of large scald burns, in which rats were not fluid resuscitated.

What is new in the current study

Induction of brief, mild therapeutic hypothermia does not prolong survival in a fluid resuscitated rat model of large scald burns.
elSSN: $2383-4625$

Received: 25 July 2014

Revised: 7 August 2014

Accepted: 17 August 2014

Correspondence to: Adam J. Singer Department of Emergency Medicine, Stony Brook University, Stony Brook, NY 11794-8300, USA

E-mail: adam.singer@stonybrookmedicine.edu

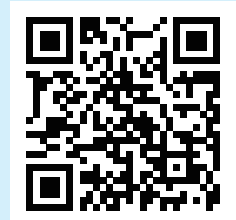

How to cite this article:

Tan N, Thode HC Jr, Singer AJ. The effect of controlled mild hypothermia on large scald burns in a resuscitated rat model. Clin Exp Emerg Med 2014;1(1):56-61.

This is an Open Access article distributed under the terms of the Creative Commons Attribution Non-Commercial License (http:// creativecommons.org/licenses/by-nc/3.0/). 


\section{INTRODUCTION}

Mild therapeutic hypothermia has been evaluated for several clinical conditions, including cardiac arrest, myocardial infarction and stroke..$^{1-5}$ The Hypothermia Study Group demonstrated that mild hypothermia after cardiac arrest resuscitation increased favorable neurological outcome and reduced overall mortality following ventricular fibrillation. ${ }^{6}$ More recently, Testori et al. ${ }^{7}$ showed that mild hypothermia supported favorable neurological outcome and mortality following non-shockable rhythms. While the exact effects of hypothermia are unknown, a reduction in metabolic rate, inflammation and oxidative stress all may play a role. However, the role of cooling in burn treatment remains controversial. A large number of animal and clinical studies demonstrate improved outcomes with local surface cooling of burns at room temperature. $^{8-41}$ In contrast, Ofeigson ${ }^{20,21}$ and Ofeigson et al. ${ }^{22}$ showed that cooling of large scald burns in rats increased mortality. Subsequent studies in other animal populations also demonstrated similar outcomes. In addition data from trauma and surgical patients indicate that spontaneous hypothermia worsens outcomes. ${ }^{42-49}$ As a result, burn specialists generally avoid excessive cooling in treatment protocols for fear of inducing hypothermia, skin necrosis, and worsening shock, among other negative outcomes.

A number of cytokines, such as interleukin (IL)-6, IL-1 beta, and tumor necrosis factor (TNF)-alpha, contribute to the pro-inflammatory state in thermal injury. TNF-alpha is thought to promote wound progression by delaying neutrophil apoptosis and inducing keratinocyte apoptosis. ${ }^{50}$ Yeh et al. ${ }^{51}$ found a significant difference in TNF-alpha serum levels between thermal injury survivors and non-survivors. In addition, burn injury is thought to induce the release of reactive oxygen and nitrogen species, further contributing to injury progression and the systemic inflammatory response syndrome. ${ }^{52-54}$ These mechanisms also play a role in the pathogenesis of myocardial infarction, stroke and post cardiac arrest where hypothermia is thought to blunt these responses. As a result, we thought that mild controlled hypothermia might also have a beneficial role in burn induced injury.

Earlier animal models demonstrating worse outcome with hypothermia focused on superficial cooling and not core cooling. Additionally, hypothermia was neither controlled nor mild. We had previously shown that controlled mild hypothermia improved mortality in rats..$^{55}$ However, a major limitation to our earlier study was that the animals were not fluid resuscitated following burn injury. In a typical clinical scenario, aggressive early fluid resuscitation would be administered.

The current study was designed to assess the effects of mild therapeutic hypothermia in a large scald injury rat model in which the animals received fluid resuscitation. We hypothesized that controlled core cooling would improve overall mortality in a fluid resuscitated rat model of large scald burns.

\section{METHODS}

\section{Study design}

The study hypothesis was tested using a prospective randomized controlled experimental animal study. The study was conducted in an accredited laboratory animal research facility with approval by the Institutional Animal Care and Handling Committee. Housing and care for animals was managed under National Research Council guidelines. ${ }^{56}$

\section{Animals}

Forty Sprague-Dawley rats weighing between 250-300 g were obtained from Charles River Laboratories in Wilmington, MA, USA. Animals were acclimated for 1-week prior to experimentation on standard rat chow while exposed to intermittent 12-hour cycles of light and dark.

\section{Study protocol}

Forty Sprague-Dawley rats were anesthetized with $40 \mathrm{mg} / \mathrm{kg}$ intramuscular ketamine and $5 \mathrm{mg} / \mathrm{kg}$ xylazine, with supplemental inhalational isoflurane $1 \%-5 \%$ as needed. A single full-thickness scald burn covering $40 \%$ of the total body surface area (TBSA) was created on each rat using a Mason-Walker template placed in boiling water $\left(100^{\circ} \mathrm{C}\right)$ for a period of 10 seconds. $^{57}$

Immediately after injury, the rats were fluid resuscitated. The fluid requirement was determined using the Parkland formula (4 $\mathrm{mL} / \%$ TBSA burn $/ \mathrm{kg}$ ). Half of the fluid requirement was injected as normal saline into the peritoneal cavity following burn induction. The second half of the fluid requirement was injected into the peritoneal cavity eight hours later.

\section{Induction of mild controlled hypothermia}

The rats were randomized to a hypothermic $(n=20)$ or normothermic $(n=20)$ group. In the experimental group, mild hypothermia was induced by administering cooled $\left(4^{\circ} \mathrm{C}\right)$ resuscitation fluids 30 minutes after burn injury. Following fluid resuscitation with cooled normal saline, the core temperature was maintained at $2^{\circ} \mathrm{C}$ below baseline by applying an ice or heat pack when necessary. Core temperature was monitored with a rectal thermometer. After two hours of hypothermia, the rats were re-warmed back to baseline temperature using a heating pad and received $0.5 \mathrm{mg} / \mathrm{kg}$ buprenorphine by intraperitoneal injection to control 
pain. We based the duration of hypothermia and rewarming on an earlier cooling study of acute lung injury on rats. ${ }^{58}$ These durations of cooling and rewarming were also found to be effective in our previous animal study. ${ }^{55}$ The rats were then monitored until recovery from anesthesia and returned to their cages. The wounds were left undressed, and additional buprenorphine was given intramuscularly as needed for pain.

Rats that appeared lethargic, lost $>15 \%$ of pre-experiment weight, failed to eat, drink or ambulate were euthanized with $\mathrm{CO}_{2}$ inhalation. The rats were monitored until death or for a period of seven days, whichever was greater. The primary outcome was death.

\section{Data analysis}

Continuous data (e.g., temperature) are presented as a means with standard deviations. Categorical data (e.g., survival) are presented as counts and percentages. A Kaplan-Meier analysis and log-rank test was used to compare the difference in survival between the two groups. The primary outcome, survival, was compared between the two groups using the $\chi^{2}$ or Fisher exact test. We tested assumptions of the temperature data for normality with the Shapiro-Wilk test, sphericity with the Mauchly test, and equality of variance with Levene test. The temperature profiles over time from baseline to 150 hours were then compared with repeated-measures analysis of variance, the between group factor being group membership. We included group/temperature interaction to the model to compare the shape of the temperature profile. A P-value of 0.05 was considered statistically significant. Data were analyzed using SPSS ver. 17.0 (SPSS Inc., Chicago, IL, USA). Based on our prior study, a sample of 20 burns in each group had $85 \%$ power to detect a difference of $20 \%$ in survival rates at seven days.

\section{RESULTS}

Full thickness burn injury was confirmed by hematoxylin and eosin stain (H\&E) histology. The mean baseline temperature for the normothermic group was $35.3^{\circ} \mathrm{C}$ and for the hypothermic group was $35.2^{\circ} \mathrm{C}$. The mean temperatures after the cooling period were $32.5^{\circ} \mathrm{C}$ for the hypothermic group and $35.6^{\circ} \mathrm{C}(\mathrm{P}=0.03)$ for the normothermic group. The variation in core temperature during the two-hour recovery period is shown in Fig. 1.

Complete temperature data was available for 33 rats. Six normothermic and 1 hypothermic rats did not have complete temperature data and were excluded from the temperature analysis. Three normothermic rats were censored prior to the study endpoint. Two hypothermic rats were censored prior to the study

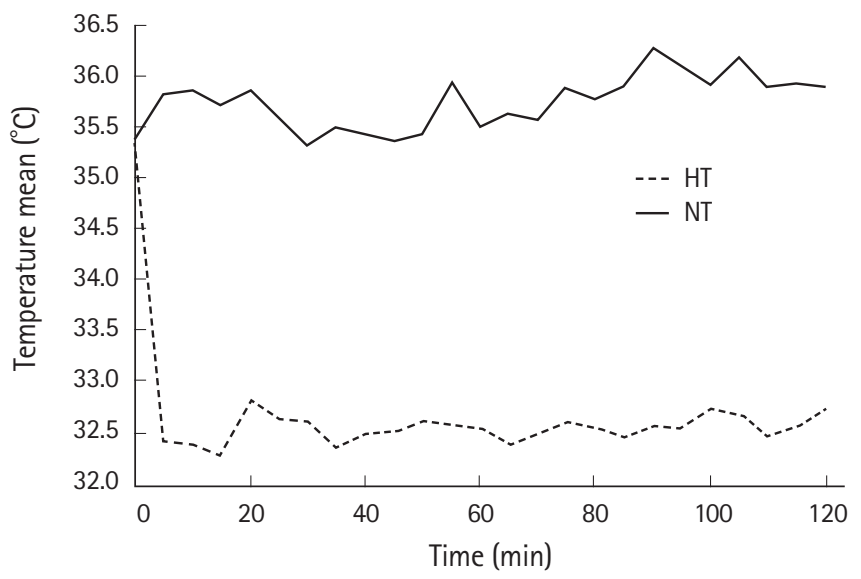

Fig. 1. Comparison of core temperature profiles in study groups. HT, hypothermia; NT, normothermia.

conclusion. These rats were assumed to have survived to the endpoint in our analysis.

The number of rats that expired at each time interval were: at 1 hour, 4 normothermic and zero hypothermic animals; at 10 hours, 2 from each group; at 24 hours, zero normothermic and 1 hypothermic; at 48 hours, 2 normothermic and 2 hypothermic; 72 hours, 1 normothermic and 1 hypothermic animals; and at 120 hours, 1 normothermic and 1 hypothermic animals. There were no additional deaths after 120 hours. The mean survival times were 100 hours for the normothermic group (95\% confidence interval [Cl], 68 to 132) and 124 hours for the hypothermic group (95\% Cl, 98 to 150) as shown in Fig. 2. The mean time to survival of the hypothermic rats was not significantly greater than that of the normothermic rats $(P=0.33)$.

\section{DISCUSSION}

Our results indicate that mild controlled hypothermia when induced with intraperitoneal fluid resuscitation did not significantly reduce mortality or prolong survival in our rat model of large scald burn injuries. These results were unexpected in view of a previous study from our laboratory, which demonstrated improved survival in non-fluid resuscitated rats with large scald burn injuries using similar hypothermic conditions. ${ }^{55}$

There are several possible reasons why our study hypothesis was not confirmed in addition to the most obvious one, that systemic hypothermia is ineffective. In the current study, fluid resuscitation was given as two large intraperitoneal boluses separated by eight hours. In contrast, continuous intravenous fluid resuscitation is used in the clinical scenario. Overzealous and rapid fluid administration may have resulted in the abdominal compartment syndrome or volume overload that may have eliminated any pos- 


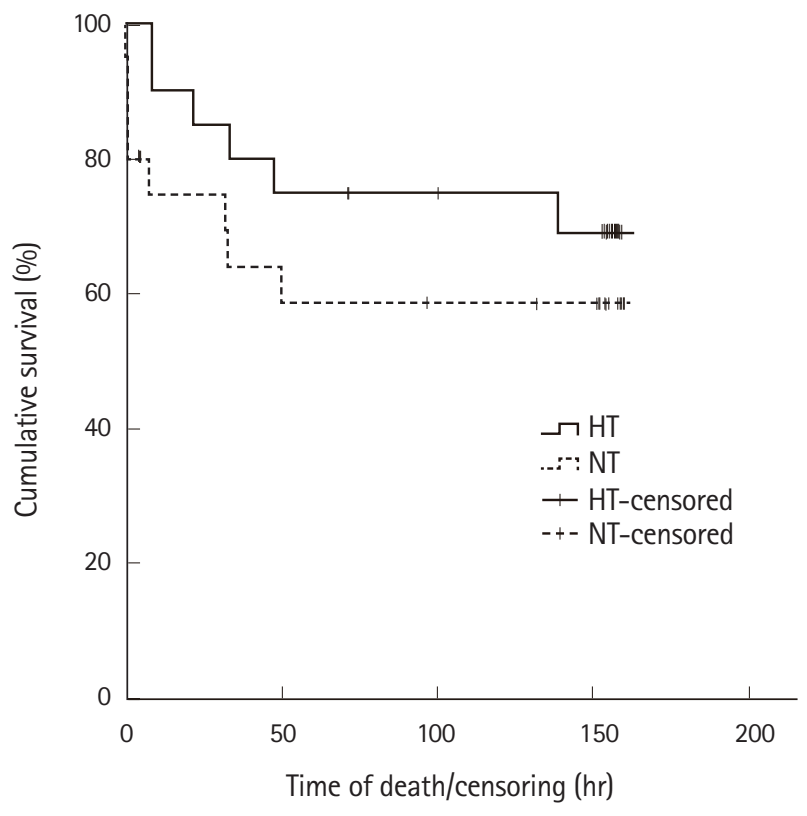

Fig. 2. Survival curves for study groups. HT, hypothermia; NT, non-hypothermia.

sible beneficial effects of mild therapeutic hypothermia. This may be similar to the phenomenon of "fluid creep" described in humans when excessive intravenous fluids are administered. ${ }^{59}$

It is also possible that the duration of hypothermia may have been too short to result in any benefit. Indeed, after cardiac arrest in humans much longer periods of hypothermia are maintained. We chose a two-hour period based on the success in prior rat studies. ${ }^{55,58}$ It is also possible that the method and speed of rewarming after hypothermia were inappropriate despite success with similar methods in the prior un-resuscitated animal model.

A recent large study of survivors of cardiac arrest demonstrated that maintaining a temperature of $36^{\circ} \mathrm{C}$ was as effective as inducing a mild hypothermia of $32^{\circ} \mathrm{C}-34^{\circ} \mathrm{C} .{ }^{60}$ Thus it is also possible that a different target temperature may have been more effective than the one studied by our group. It is also possible that our study was underpowered to detect small differences in survival that still might be clinically significant.

In addition to the limitations noted above with regards to the methods of fluid resuscitation, cooling and rewarming, several other limitations should be noted. Our study may have been underpowered to detect any difference in the primary outcome, mortality. Most importantly, while the rat scald burn model has been commonly used, it is unclear how representative it is of human burns. Thus our results may not generalize to the clinical scenario.

In conclusion, induction of brief mild hypothermia by administration of intraperitoneal fluid boluses does not significantly pro- long survival in a resuscitated rat model of large scald burns. Further studies should consider the use of continuous intravenous fluid administration as well as extension of the cooling and warming periods before abandoning mild therapeutic hypothermia for burns.

\section{CONFLICT OF INTEREST}

No potential conflict of interest relevant to this article was reported.

\section{REFERENCES}

1. Krieger DW, Yenari MA. Therapeutic hypothermia for acute ischemic stroke: what do laboratory studies teach us? Stroke 2004;35:1482-9.

2. Bernard $S A$, Jones $B M$, Horne MK. Clinical trial of induced hypothermia in comatose survivors of out-of-hospital cardiac arrest. Ann Emerg Med 1997;30:146-53.

3. Bernard SA, Gray TW, Buist MD, et al. Treatment of comatose survivors of out-of-hospital cardiac arrest with induced hypothermia. N Engl J Med 2002;346:557-63.

4. Rivard AL, Gallegos RP, Bianco RW, Liao K. The basic science aspect of donor heart preservation: a review. J Extra Corpor Technol 2004;36:269-74.

5. Bernard SA, Buist M. Induced hypothermia in critical care medicine: a review. Crit Care Med 2003;31:2041-51.

6. Hypothermia after Cardiac Arrest Study Group. Mild therapeutic hypothermia to improve the neurologic outcome after cardiac arrest. N Engl J Med 2002;346:549-56.

7. Testori C, Sterz F, Behringer W, et al. Mild therapeutic hypothermia is associated with favourable outcome in patients after cardiac arrest with non-shockable rhythms. Resuscitation 2011;82:1162-7.

8. Raghupati N. First-aid treatment of burns: efficacy of water cooling. Br J Plast Surg 1968;21:68-72.

9. Grounds M. Immediate surface cooling in treatment of burns. Med J Aust 1967;2:846-7.

10. Berberian GM. Temporary regional surface cooling and longterm heparinization in the therapy of burns. Surgery 1960; 48:391-3.

11. Shulman AG. Ice water as primary treatment of burns: simple method of emergency treatment of burns to alleviate pain, reduce sequelae, and hasten healing. JAMA 1960;173:1916-9.

12. Purdue GF, Layton TR, Copeland CE. Cold injury complicating burn therapy. J Trauma 1985;25:167-8.

13. King TC, Price PB, Reynolds LE. Local edema and capillary per- 
meability associated with burn wounds. Surg Forum 1956; 6:80-4.

14. Jakobsson OP, Arturson G. The effect of prompt local cooling on oedema formation in scalded rat paws. Burns Incl Therm Inj 1985;12:8-15.

15. Blomgren I, Eriksson E, Bagge U. The effect of different cooling temperatures and immersion fluids on post-burn oedema and survival of the partially scalded hairy mouse ear. Burns Incl Therm Inj 1985;11:161-5.

16. Blomgren I, Eriksson E, Bagge U. Effect of cold water immersion on oedema formation in the scalded mouse ear. Burns Incl Therm Inj 1982;9:17-20.

17. de Camara DL, Raine T, Robson MC. Ultrastructural aspects of cooled thermal injury. J Trauma 1981;21:911-9.

18. King TC, Zimmerman JM. Optimum temperatures for postburn cooling. Arch Surg 1965;91:656-7.

19. King TC, Zimmerman JM. First-aid cooling of the fresh burn. Surg Gynecol Obstet 1965;120:1271-3.

20. Ofeigsson 0J. First-aid treatment of scalds and burns by water cooling. Postgrad Med 1961;30:330-8.

21. Ofeigsson 0J. Water cooling: first-aid treatment for scalds and burns. Surgery 1965;57:391-400.

22. Ofeigsson OJ, Mitchell R, Patrick RS. Observations on the cold water treatment of cutaneous burns. J Pathol 1972;108:145-50.

23. King TC, Zimmerman JM, Price PB. Effect of immediate shortterm cooling on extensive burns. Surg Forum 1962;13:487-8.

24. Shulman $A G$, Wagner K. Effect of cold water immersion on burn edema in rabbits. Surg Gynecol Obstet 1962;115:557-60.

25. Demling RH, Mazess RB, Wolberg W. The effect of immediate and delayed cold immersion on burn edema formation and resorption. J Trauma 1979;19:56-60.

26. Moore DH, Worf DL. Effect of temperature on the transfer of serum proteins into tissues injured by tourniquet and by scald. Am J Physiol 1952;170:616-23.

27. Courtice FC. The effect of local temperature on fluid loss in thermal burns. J Physiol 1946;104:321-45.

28. Langohr JL, Rosenfeld L, Owen CR, Cope O. Effect of therapeutic cold on the circulation of blood and lymph in thermal burns; an experimental study. Arch Surg 1949;59:1031-44.

29. Moserova J, Behounkova E, Prouza Z. Subcutaneous temperature measurements in thermal injury. Burns 1975; 1:267-8.

30. Nguyen NL, Gun RT, Sparnon AL, Ryan P. The importance of immediate cooling: a case series of childhood burns in Vietnam. Burns 2002;28:173-6.

31. Li C, Yu D, Li MS. Clinical and experiment study of cooling therapy on burned wound. Zhonghua Yi Xue Za Zhi 1997;77: 586-8.

32. Saranto JR, Rubayi S, Zawacki BE. Blisters, cooling, anti- thromboxanes, and healing in experimental zone-of-stasis burns. J Trauma 1983;23:927-33.

33. Ofeigsson 0J. Observations and experiments on the immediate cold-water treatment of burns and scalds. Br J Plast Surg 1959;12:104-19.

34. Jandera V, Hudson DA, de Wet PM, Innes PM, Rode H. Cooling the burn wound: evaluation of different modalites. Burns 2000;26:265-70.

35. Raine TJ, Heggers JP, Robson MC, London MD, Johns L. Cooling the burn wound to maintain microcirculation. J Trauma 1981;21:394-7.

36. King TC, Price PB. Surface cooling following extensive burns. JAMA 1963;183:677-8.

37. Rose HW. Initial cold water treatment for burns. Northwest Med 1936;35:267-70.

38. Sawada $Y$, Urushidate $S$, Yotsuyanagi T, Ishita K. Is prolonged and excessive cooling of a scalded wound effective? Burns 1997;23:55-8.

39. Matthews RN, Radakrishnan T. First-aid for burns. Lancet 1987;1:1371.

40. Cuttle L, Kempf M, Kravchuk O, et al. The optimal temperature of first aid treatment for partial thickness burn injuries. Wound Repair Regen 2008;16:626-34.

41. Rajan V, Bartlett N, Harvey JG, et al. Delayed cooling of an acute scald contact burn injury in a porcine model: is it worthwhile? J Burn Care Res 2009;30:729-34.

42. Jurkovich GJ, Greiser WB, Luterman A, Curreri PW. Hypothermia in trauma victims: an ominous predictor of survival. J Trauma 1987;27:1019-24.

43. Gentilello LM, Jurkovich GJ, Stark MS, Hassantash SA, O'Keefe $\mathrm{GE}$. Is hypothermia in the victim of major trauma protective or harmful? A randomized, prospective study. Ann Surg 1997; 226:439-47.

44. Peng RY, Bongard FS. Hypothermia in trauma patients. J Am Coll Surg 1999;188:685-96.

45. White $C E$, Renz EM. Advances in surgical care: management of severe burn injury. Crit Care Med 2008;36:S318-24.

46. Rutherford EJ, Fusco MA, Nunn CR, Bass JG, Eddy VA, Morris JA Jr. Hypothermia in critically ill trauma patients. Injury 1998; 29:605-8.

47. Ferrara $A$, MacArthur JD, Wright HK, Modlin IM, McMillen MA. Hypothermia and acidosis worsen coagulopathy in the patient requiring massive transfusion. Am J Surg 1990;160: 515-8.

48. Cosgriff N, Moore EE, Sauaia A, Kenny-Moynihan M, Burch $J M$, Galloway B. Predicting life-threatening coagulopathy in the massively transfused trauma patient: hypothermia and 
acidoses revisited. J Trauma 1997;42:857-61.

49. Watts DD, Trask A, Soeken $K$, Perdue P, Dols S, Kaufmann C. Hypothermic coagulopathy in trauma: effect of varying levels of hypothermia on enzyme speed, platelet function, and fibrinolytic activity. J Trauma 1998;44:846-54.

50. Shupp JW, Nasabzadeh TJ, Rosenthal DS, Jordan MH, Fidler P, Jeng JC. A review of the local pathophysiologic bases of burn wound progression. J Burn Care Res 2010;31:849-73.

51. Yeh $F L$, Lin $W L$, Shen HD, Fang RH. Changes in serum tumour necrosis factor-alpha in burned patients. Burns 1997;23:6-10.

52. Milde LN. Clinical use of mild hypothermia for brain protection: a dream revisited. J Neurosurg Anesthesiol 1992;4:211-5.

53. Small DL, Morley P, Buchan AM. Biology of ischemic cerebral cell death. Prog Cardiovasc Dis 1999;42:185-207.

54. Polderman KH. Application of therapeutic hypothermia in the ICU: opportunities and pitfalls of a promising treatment modality. Part 1: Indications and evidence. Intensive Care Med
2004:30:556-75.

55. Singer AJ, Wang E, Taira BR, Steinhauff N, Rooney J, Zimmerman T. Controlled mild hypothermia prolongs survival in a rat model of large scald burns. Acad Emerg Med 2011;18:287-91.

56. National Research Council. Guide for the care and use of laboratory animals. Washington, DC: National Academies Press; 1996.

57. Walker HL, Mason AD Jr. A standard animal burn. J Trauma 1968;8:1049-51.

58. Kim K, Kim W, Rhee JE, et al. Induced hypothermia attenuates the acute lung injury in hemorrhagic shock. J Trauma 2010;68: 373-81.

59. Saffle Jl. The phenomenon of "fluid creep" in acute burn resuscitation. J Burn Care Res 2007;28:382-95.

60. Nielsen N, Wetterslev J, Cronberg T, et al. Targeted temperature management at $33^{\circ} \mathrm{C}$ versus $36^{\circ} \mathrm{C}$ after cardiac arrest. $\mathrm{N}$ Engl J Med 2013;369:2197-206. 